\title{
How Does Authoritarian Leadership Lead to Employee Unethical Pro- organizational Behavior? The Mediating Effect of Work Stressor and Moral Disengagement
}

\author{
Kang-Hwa Shaw ${ }^{1, a}$, Hung-Yi Liao 2, b \\ ${ }^{1}$ School of Management, Shandong University, Shandong, 250100, China; \\ ${ }^{2}$ College of Philosophy, Law and Political Science, Shanghai Normal University, Shanghai, 200234, \\ China; \\ akevinshaw99@sdu.edu.cn, b2118758310@qq.com
}

\begin{abstract}
Keywords: authoritarian leadership, unethical pro-organizational behavior, work stressor, moral disengagement.
\end{abstract}

\begin{abstract}
Along with the developing of the research on Organizational Behavior, more and more scholars pay attention to the unethical pro-organizational behavior (UPB). Drawing on the S-O-M Model, we explored the relationship between the authoritarian leadership and employees' UPB, and the mediation effect of work stressor and moral disengagement on it. Using questionnaire survey, we collected data at two time-points and obtained 98 usable observations for hypothesis testing. The results of regression analyses showed that the authoritarian leadership can predict employees' UPB through the work stressor and moral disengagement. We discussed the implications, limitations, and future research directions.
\end{abstract}

\section{Introduction}

The attitude and behavior of employees are always concerned by organizational behavior field. Recently, more studies focus on the employee's unethical behavior, because there are couple unethical events explored by news around the world, such as Enron incident in the US, Barings Bank in the UK, and Sanlu group in China. Unethical behavior is the employee breaching the standard in the organization (Kish-Gephart, Harrison \& Treviño, 2010) [1]. In the previous studies, unethical behavior links to a personal benefit (Greenberg, 2002) [2], or revenge the organization. However, a study found that the employee may make an unethical behavior for the benefit of the organization. Umphress, Bingham, and Mitchell, (2010) put forward to call this altruistic behavior within an unethical behavior is "unethical pro-organizational behavior, UPB" [3].

In essence, searching for the motivation of UPB in firms (Umphress \& Bingham, 2011) is an interesting question [4]. Much recent research highlights that the style of leadership can be an important source of UPB, such as ethical leadership (Miao, et al., 2013) and transformational leadership (Effelsberg, Solga, \& Gurt, 2013) [5][6]. Indeed, in the film, the employee has uncertainty and insecurity because the supervisor controls the most resources and decision-making power (Wu, 2008) [7]. Thus, the leadership might influence on employee's behavior, (e.g., UPB).

Paternalistic leadership which is a leadership theory rooted in Chinese traditional culture exists in the organizations of Chinese context. There are empirical studies on the effectiveness of paternalistic leadership, found that benevolent leadership and moral leadership have positive effects on employee's attitude and behavior (e.g., organizational commitment and performance "Cheng, Huang, \& Chou, 2002") [8]; however, the effectiveness of authoritarian leadership has been disputed, e.g., having the negative impact on performance (Wu, et al., 2012) [9], but some sstudies claim that it is a positive influence (Chen, et al., 2014) or non-significant (Zhang, He, \& Gu, 2009)

[10][11]. These results have shown the significance and value of paternalistic leadership in Chinese organizations and clarified its explanation on employee's attitude and behavior. Moreover, refer to $\mathrm{Wu}$ (2008) [7], there are many studies to present that the authoritarian leadership can effectively 
predict the employees' response. Therefore, we are curious about a question, would authoritarian leadership ask the employee to do the unethical action for the benefit of the organization?

Also, more recent studies have advocated that the employee perceived mistreatment by the supervisor (e.g., abusive supervision, "Tepper, 2000") [12] could have the negative influence on the outcome (e.g., organization commitment) and cause to have the work stress. Even work stress can motivate to finish the task, the employee still gets pressure in this process. On the other hand, after the employee taking the task from the authoritarian leadership, he/she must have work stress to finish this task effectiveness. Consequently, the employee might utilize moral disengagement to complete it even doing an unethical behavior. Therefore, we will explicate the work stresses and moral disengagement in this potential psychological path. Figure 1 presents the theoretical framework investigated in this study, which guides the development of the research hypotheses.

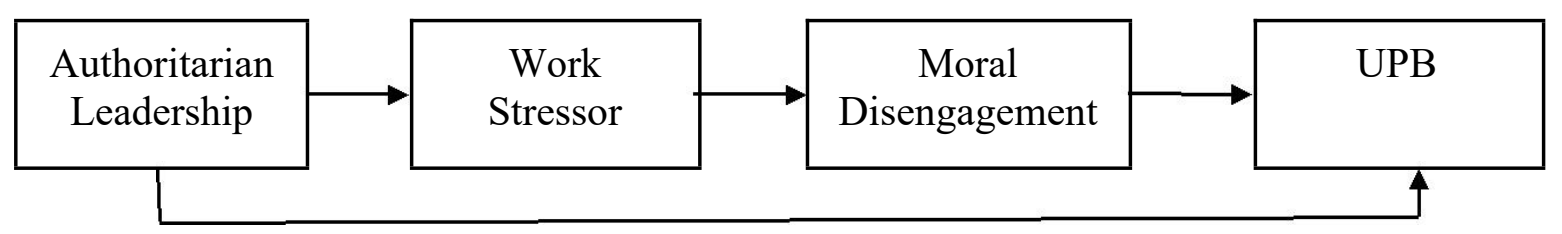

Figure 1 Hypothetical Model

\section{Literature Review and Hypothesis}

\section{Authoritarian Leadership and Unethical Pro-Organizational Behavior}

Farh and Cheng (2000, pp. 84) defined that paternalistic leadership is a style that "combines strong discipline and authority with fatherly benevolence and moral integrity couched in a personality atmosphere. [13]" Refer to $\mathrm{Wu}$ (2008), disputed on the outcome of authoritarian leadership, we are interesting to explore how authoritarian leadership motivates the employee's UPB [7].

Authoritarian leadership can be described as a leader declares his/her authority and control over the employees to demand unquestionable obedience (Cheng, et al.,2004) [14]. Furthermore, it was found that authoritarian is negatively influenced to employees' outcomes, e.g., OCB and commitment (Cheng, et al., 2002) [8]. Also, Otken and Cenkci (2007) represent that the authoritative behavior of leader influences employees to follow the rule. It might cause the employees have to make the task done and consider whether a decision violates the laws [28]. Therefore, we can understand that the manager could ask the employees to do these unethical actions for the short-term benefit of the organization based on improving the performance. On the opposite, the employees might do the unethical decision-making (e.g., lying) to attach the goal, and then have the opportunity to do UPB. As such, our hypothesis is as follows:

Hypothesis 1. Authoritarian leadership is positively related to employee unethical proorganization behavior.

\section{The Mediating Role of Work Stressor and Moral Disengagement}

Based on the Stimulus-Organism-Response (S-O-M Model)(Mehrabian \& Russell, 1974) [15], we consider that the authoritarian leadership is a stimulus of the work environment to the employees. After the employees sense the information of work environment, each of them has the different trait will decode it into the diverse meaning. Thus, the meaning is a perceptive and psychological feeling to cause them reacting to avoidance behavior.

Therefore, when the employees need to follow the order of authoritarian leadership, they will show their obedience is likely to hide their suffering pressure. Farh and Cheng (2000) indicated that 
the authoritarian leadership is one-way communication and a lack of feedback to let the employee follow his/her order [13]. Also, the authoritarian leadership is an important factor of work stress in the workplace. The reason is that this kind of powerful leadership style can make the employees have the high pressure to consider "won or lost" when they are in the task (Liu, Qi, \& $\mathrm{Xu}, 2017)$ [16]. Therefore, the employees will have the pressure and bad consequences.

Even we can realize the employees might do the unethical behavior after the employees perceive the work stress, we are curious about what is their motivation to do UPB. Based on the S-O-M Model and social cognitive theory, we can consider that moral disengagement is a mechanism to influence an individual's unethical action (Bandura, 1986) [17]. More concretely, an individual redefines his/her immoral action to make them less harmful, minimize his/her responsibilities in his/her behavioral consequences (Bandura, 1999) [18].

This study argues that moral disengagement could be the meditation between work stress and UPB. Kish-Gephart, et al. (2010) claimed that when the employee has the stronger personal utility, his/her moral disengagement is a positive influence to unethical decision-making [1]. In addition, for doing the unethical action, the individual would use the moral disengagement to weaken the internal moral agency. In the organization, when the employees have the heavy workload to emerge more stress and less organizational support, they might have the moral disengagement to do the anti-production behavior (Fida, et al., 2015) [19]. Therefore, we can understand when the employees have work stress to accomplish the task, they intend to do an unethical behavior.

Furthermore, the interaction of the environment with individual reactions leads to stress. For the employees, the most immediate situational factor in the workplace is leadership. Therefore, the leadership could influence the employee's job stress. Some studies claimed that the moral disengagement is the mediation between leadership style and negative outcomes (e.g., unethical behavior, "Palmer, 2013") [20]. If the employees are facing the pressure of work within the acceptable range, they will take the initiative to adopt positive coping strategies. After they are overcoming the task, they will obtain the stronger achievability. In the opposite, if they perceive the work stress which they consider this is insurmountable, it will have a negative impact on their job performance. by this approach, the authoritarian leadership can give the employee's work stress and ask them to have done the mission well. Therefore, the employees desire to have the task done for showing their pro-organizational behavior without considering they did the unethical behavior or not. For these aspects, this study hypothesizes:

Hypothesis 2. Authoritarian leadership is indirectly and positively related to employee unethical pro-organization behavior via work stressor and moral disengagement.

\section{Methods}

\section{Participants and Procedure}

The study sample comprised full-time employees of several companies in China. We examined our hypotheses by using survey data, which we obtained after distributing the questionnaire by relying on the assistance of the department manager. To reduce the problem of causal confusion, we tested the hypotheses with data collected at two points of time. At time 1, we measured authoritarian leadership, work stressor, and moral disengagement. At time 2, we measured employees' UPB. The second wave of data collection took place two weeks after the first wave.

We distributed 108 employees responded to the time- 1 survey ( $98.2 \%$ response rate). In addition, 101 employees responded to time- 2 survey. After excluding 3 incomplete surveys, there were 98 employees who responded to both time 1 and time 2 surveys (89.1\% useable response rate). Among the respondents, $58.2 \%$ were male and $71.4 \%$ were college. The average age was 26.66 years old $(\mathrm{SD}=6.74)$, and the average organizational tenure was 3.39 years $(\mathrm{SD}=6.46)$. In addition, $37.8 \%$ were from state-owned enterprise and $32.7 \%$ were engaged IT electronics industry. 


\section{Measures}

Following the translation and back-translation procedure suggested by Brislin (1980) [21], we created Chinese versions of measures for authoritarian leadership, work stressor, moral disengagement, and UPB.

Authoritarian leadership. Authoritarian leadership was measured using the 9-item scale developed by Cheng, et al. (2004) [14]. Respondents were asked to rate the authoritarian leadership of their immediate supervisor using a six-point Likert scale (where $1=$ strongly disagree and $6=$ strongly agree). Sample items included "My supervisor asks me to obey his/her instructions completely." and "My supervisor always has the last say in the meeting." The Cronbach alpha for this scale was 0.85 .

Work stressor. Work stressor was measured using the 7-item scale developed by Zhang, et al. (2014) [22]. Respondents were asked to rate the frequency of these demands in your daily work using a six-point Likert scale (where $1=$ never and $6=$ extremely often e). Sample items included "having to complete a lot of work." and "having to perform complex tasks." The Cronbach alpha for this scale was 0.87 .

Moral disengagement. Moral disengagement was measured using the 8 -item scale developed by Moore, et al. (2012) [23]. Respondents were asked to rate the extent to which their moral disengagement using a six-point Likert scale (where $1=$ strongly disagree and $6=$ strongly agree). Sample items included "It is okay to spread rumors to defend those you care about." and "Taking something without the owner's permission is okay as long as you're just borrowing it." The Cronbach alpha for this scale was 0.94 .

Unethical pro-organizational behavior. Unethical pro-organizational behavior (UPB) was measured using the 6-item self-report scale adapted from Umphress, et al. (2010) [4]. Respondents required to rate the extent to which they engaged in UPB using a six-point Likert scale (where $1=$ strongly disagree and $6=$ strongly agree). Sample items included "If it would help my organization, I would misrepresent the truth to make my organization look good." and "If it would benefit my organization, I would withhold negative information about my organization." The Cronbach alpha for this scale was 0.95 .

Control variables. As prior research has shown that demographic characteristics (i.e., gender, age, education, tenure) may influence the extent to which individuals engage in unethical behavior (Kish-Gephart, et al., 2010; Miao, et al., 2013) [1] [5], we controlled for the effects of demographic characteristics.

\section{Analysis and Results}

The data analysis was undertaken in two steps. First, confirmatory factor analysis (CFA) was conducted using LISREL 8.7 to test the discriminant validity of the multiple-item measures used in the study. Second, hierarchical regression analysis was conducted using SPSS 20.0 to test the hypotheses.

\section{Confirmatory Factor Analysis}

Following Anderson and Gerbing's (1988) [24] recommendations concerning convergent and discriminate validities, we formed a four-factor CFA model (as shown in Table 1) and found that all items had significant factor loadings on the factor identified a priori at a significance level of .05. Inspections of the fit indices indicated that although the chi-square was significant, $\chi 2(399)=$ $726.38, \mathrm{p}<0.05$, other practical fit indices also fell within acceptable ranges (RMSEA $=0.09$, CFI

$=0.92, \mathrm{IFI}=0.92, \mathrm{NNFI}=0.92, \mathrm{SRMR}=0.09)$, suggesting the model was acceptable $(\mathrm{Hu} \&$ Bentler, 1999) [25]. A test for CMV was conducted using Harman's recommendations. A onefactor model was compared to that of the proposed four-factor model. Comparison of goodness-offit indices showed that the one-factor model was significantly worse than that of the 
four-factor model $(\Delta \chi 2(6)=1393.94, \mathrm{p}<0.01)$. These results suggest that CMV is not a serious threat to the findings of this study (Podsakoff, et al. 2003) [26]. We also compared the goodness-offit indices of the four-factor model with that of a three-factor model in which items measuring authoritarian leadership and work stressor were loaded onto a single factor. Again, the indices of the three-factor model were significantly worse $(\Delta \chi 2(1)=364.03, \mathrm{p}<0.01)$, suggesting the four-factor model fitted the data best. Finally, we also compared the goodness-of-fit indices of the four-factor model with that of a two-factor model in which items measuring authoritarian leadership, work stressor and moral disengagement loaded onto a single factor. Again, the indices of the two-factor model were significantly worse $\left(\Delta \chi^{2}(3)=624.27, \mathrm{p}<0.01\right)$, suggesting the four-factor model fitted the data best. Results of these chi-square tests further support the discriminate validity of the fourfactor model.

Table 1 Results of the Measurement Model Analysis

\begin{tabular}{lccccccccc}
\hline \multicolumn{1}{c}{ Model } & $\chi 2$ & $\mathrm{df}$ & $\Delta \chi^{2}$ & $\Delta \mathrm{df}$ & RMSEA & CFI & IFI & NNFI & SRMR \\
\hline Four-factor model & 726.38 & 399 & -- & -- & 0.09 & 0.92 & 0.92 & 0.92 & 0.09 \\
Three-factor model & 1090.41 & 400 & $364.03 * *$ & 1 & 0.13 & 0.88 & 0.88 & 0.87 & 0.12 \\
Two-factor model & 1350.65 & 402 & $624.27^{* *}$ & 3 & 0.16 & 0.84 & 0.85 & 0.83 & 0.13 \\
One-factor model & 2120.32 & 405 & $1393.94 * *$ & 6 & 0.21 & 0.73 & 0.74 & 0.71 & 0.17 \\
\hline
\end{tabular}

Note. Four-factor model was hypothesized model; Three-factor model was combining authoritarian leadership and work stressor; Two-factor model was combining authoritarian leadership, work stressor and moral disengagement; One-factor model was combining all variables. ${ }^{* *} p<0.01$.

\section{Descriptive Statistics and Correlations Analysis}

Table 2 lists the means, standard deviations, and correlations among all of the variables. As expected, authoritarian leadership was positively correlated with work stressor $(\mathrm{r}=0.30, \mathrm{p}<0.01)$ and unethical pro-organizational behavior $(\mathrm{r}=0.40, \mathrm{p}<0.01)$. Work stressor was positively correlated with moral disengagement $(\mathrm{r}=0.55, \mathrm{p}<0.01)$. Finally, moral disengagement was positively correlated with unethical pro-organizational behavior $(\mathrm{r}=0.54, \mathrm{p}<0.01)$.

Table 2 Means, Standard Deviations, and Correlations among the Variables

\begin{tabular}{lcccccc}
\hline \multicolumn{1}{c}{ Variables } & Means & SD & 1. & 2. & 3. & 4. \\
\hline 1. Authoritarian leadership & 3.43 & 0.88 & $(0.85)$ & & & \\
2. Work stressor & 2.82 & 0.83 & $0.30^{* *}$ & $(0.87)$ & & \\
3. Moral disengagement & 2.53 & 1.04 & $0.23^{*}$ & $0.55^{* *}$ & $(0.94)$ & \\
4. UPB & 3.31 & 1.27 & $0.40^{* *}$ & $0.36^{* *}$ & $0.54^{* *}$ & $(0.95)$ \\
\hline
\end{tabular}

Note. Numbers in parentheses are the coefficient alphas. ${ }^{*} p<0.05 ; * * p<0.01$.

\section{Hypothesis Tests}

As shown in Table 3, after controlling for the effects of demographic variables, the authoritarian leadership have remarkable positive influence on employees' UPB $(\beta=0.41, \mathrm{p}<0.001)$. Thus, Hypotheses 1 was supported. Moreover, the authoritarian leadership have remarkable positive influence on employees' work stressor $(\beta=0.26, \mathrm{p}<0.05)$. The work stressor have remarkable positive influence on employees' moral disengagement $(\beta=0.51, p<0.001)$. Finally, the moral disengagement have remarkable positive influence on employees' UPB $(\beta=0.48, p<0.001)$. Thus, Hypotheses 2 was supported.

Afterward, we used Hayes's (2013) [27] PROCESS macro (Model 6) for SPSS to test the statistical significance of these indirect effects. On the basis of our sample, we conducted the bootstrapping procedure with 2,000 random samples and a 95\% confidence level. After we controlled for demographic variables, the point estimate for the direct effect of authoritarian 
leadership on employees' UPB was 0.47 (95\% confidence interval: [0.22, 0.72]). We concluded that the authoritarian leadership was positively related to employees' UPB. Therefore, Hypotheses 1 was supported. Moreover, the point estimate for the indirect effect of authoritarian leadership on employees' UPB via work stressor and moral disengagement was 0.07 (95\% confidence interval: $[0.01,0.20])$. We concluded that the work stressor and moral disengagement were mediator between authoritarian leadership and employees' UPB. Therefore, Hypotheses 2 was supported.

Table 3 Results of the Hierarchical Regression Analysis

\begin{tabular}{|c|c|c|c|c|c|c|c|}
\hline \multirow{2}{*}{ Variables } & \multicolumn{2}{|c|}{ Work stressor } & \multicolumn{2}{|c|}{ Moral disengagement } & \multicolumn{3}{|c|}{ UPB } \\
\hline & Model 1 & Model 2 & Model 3 & Model 4 & Model 5 & Model 6 & Model 7 \\
\hline \multicolumn{8}{|l|}{ Control variables } \\
\hline Gender & 0.12 & 0.04 & 0.09 & 0.03 & 0.08 & 0.03 & -0.06 \\
\hline Age & -0.08 & -0.05 & -0.04 & 0.00 & -0.07 & -0.05 & -0.01 \\
\hline Education & 0.19 & 0.19 & 0.20 & 0.10 & $0.31 * *$ & $0.22 *$ & $0.31 * *$ \\
\hline Tenure & -0.05 & -0.06 & -0.21 & -0.18 & -0.09 & 0.01 & -0.10 \\
\hline \multicolumn{8}{|l|}{ Independent variables } \\
\hline Authoritarian leadership & & $0.26^{*}$ & & & & & $0.41 * * *$ \\
\hline Work stressor & & & & $0.51 * * *$ & & & \\
\hline Moral disengagement & & & & & \multicolumn{3}{|c|}{$0.48 * * *$} \\
\hline$R^{2}$ & 0.07 & 0.13 & 0.11 & 0.36 & 0.14 & 0.34 & 0.29 \\
\hline $\operatorname{Adj} R^{2}$ & 0.03 & 0.08 & 0.08 & 0.32 & 0.10 & 0.31 & 0.25 \\
\hline$R^{2}$ & 0.07 & $0.06^{*}$ & $0.11 *$ & $0.25 * * *$ & $0.14^{* *}$ & $0.20 * * *$ & $0.15 * * *$ \\
\hline$F$ & 1.77 & $2.76^{*}$ & $2.99 *$ & $10.28 * * *$ & $3.74 * *$ & $9.52 * * *$ & $7.61 * * *$ \\
\hline \multicolumn{8}{|c|}{ Note. Standardized beta coefficients were reported in this table. ${ }^{*} p<0.05 ;{ }^{* *} p<0.01 ;{ }^{* * *} p<0.001$} \\
\hline \multicolumn{8}{|c|}{ Table 4 Results of the Bootstrapping Analysis } \\
\hline & & & & & \multicolumn{2}{|c|}{ Estimate $(\mathrm{SE})^{\mathrm{a}}$} & $\mathrm{CI}$ \\
\hline \multicolumn{8}{|c|}{ Direct effect } \\
\hline \multicolumn{3}{|c|}{ Authoritarian leadership $\rightarrow$ UPB } & & & \multicolumn{2}{|c|}{$0.47(0.12)$} & {$[0.22,0.72]$} \\
\hline \multicolumn{8}{|c|}{ Indirect effect } \\
\hline \multicolumn{5}{|c|}{ Authoritarian leadership $\rightarrow$ Work stressor $\rightarrow$ UPB } & \multicolumn{2}{|c|}{$0.01(0.05)$} & {$[-0.08,0.11]$} \\
\hline \multicolumn{5}{|c|}{ Authoritarian leadership $\rightarrow$ Moral disengagement $\rightarrow$ UPB } & \multicolumn{2}{|c|}{$0.05(0.06)$} & {$[-0.03,0.20]$} \\
\hline \multicolumn{5}{|c|}{ Authoritarian leadership $\rightarrow$ Work stressor $\rightarrow$ Moral disengagement $\rightarrow$ UPB } & \multicolumn{2}{|c|}{$0.07(0.04)$} & {$[0.01,0.20]$} \\
\hline \multicolumn{5}{|c|}{ Total effect } & \multicolumn{2}{|c|}{$0.13(0.07)$} & {$[0.01,0.31]$} \\
\hline
\end{tabular}

Note. $\mathrm{CI}=$ confidence interval. ${ }^{\mathrm{a}}$ Bootstrapped estimates for the standard error (SE) are presented.

\section{Discussion}

This study sample comprised full-time employees of several companies in China. We concluded that the Authoritarian leadership has the positive influence on UPB, and work stressor and moral disengagement were mediator between authoritarian leadership and employees' UPB.

\section{Theoretical Implications}

This study has some important implications for existing literature related to UPB. First, in accordance with previous studies, authoritarian leadership impacts on the employee's positive behavior (i.e., performance) or negative behavior (i.e., workplace deviance behavior) (Cheng \& Farh, 2000) [1]. The current research demonstrates the importance value of authoritarian leadership for employee's UPB. Despite recent research in understanding the authoritarian leadership may lead to the employee's UPB. On the other hand, the mechanism which is the psychological path of 
employees may be considered in this relationship. The findings reflect the authoritarian leadership can trigger the sequential mediation, work stressor and moral disengagement, on the UPB.

\section{Managerial Implications}

Our study provides implications for managerial practices. Our research verified that a sequential mediation of work stressor and moral disengagement between the authoritarian leadership and UPB. In the Chinese context, there is typically hierarchical management in the organization. Sometimes, the authoritarian leadership is avoidless, so the leader should take notice of giving the order to the employees. The leaders better not use the command which means hinting the employees can do the unethical actions to give the employees task. Therefore, the employees will not perceive the pressure even it is a challenging goal. However, they can still use the positive style to finish the mission. Second, the managers should try to reduce the work stress to the employees. This way can avoid the employees doing the UPB for the job goal or task.

\section{Limitations and Suggestions for Future Research}

There are limitations in this study: (1) The sample is from the employees of the self-rating questionnaire may be a common variance, although this study of technology processing. However, it is still possible to influence the results. Therefore, suggesting that the future research should collect the pair-data from leaders and employees in order to reduce the influence caused by the common variance. (2) The effects that we observed in this study can be influenced in the Chinese contexts. It also values paternalism in the other countries, such as, South American and Eastern European (Aycan, et al., 2000) [29]. It is necessary to replicate out findings outside of the China region. (3) If future research still expands in the Chinese context, the researchers can consider the boundary (e.g., LMX quality) in the study of UPB.

\section{References}

[1] Kish-Gephart J J, Harrison D A, Treviño L K. Bad apples, bad cases, and bad barrels: Metaanalytic evidence about sources of unethical decisions at work[J]. Journal of Applied Psychology, 2010, 95(1): 1-31.

[2] Greenberg J. Who stole the money, and when? Individual and situational determinants of employee theft[J]. Organizational Behavior \& Human Decision Processes, 2002, 89(1):985-1003.

[3] Umphress E E, Bingham J B, Mitchell M S. Unethical behavior in the name of the company: the moderating effect of organizational identification and positive reciprocity beliefs on unethical proorganizational behavior[J]. Journal of Applied Psychology, 2010, 95(4):769-780.

[4] Umphress E E, Bingham J B. When employees do bad things for good reasons: Examining unethical pro-organizational behaviors[J]. Organization Science, 2011, 22(3):621-640.

[5] Miao Q, Newman A, Yu J, \& Xu, L. The relationship between ethical leadership and unethical pro-organizational behavior: Linear or curvilinear effects?[J]. Journal of Business Ethics, 2013, 116(3):641-653.

[6] Effelsberg D, Solga M, Gurt J. Transformational land follower's unethical behavior for the benefit of the company: A two-study investigation[J]. Journal of Business Ethics, 2014, 120(1):8193.

[7] $\mathrm{Wu}, \mathrm{T}$.Y. The mediating process of trust and the moderating effect of emotional intelligence on a Chinese supervisor's authoritarian leadership and a subordinate's job satisfaction and organizational commitment[J]. Indigenous Psychological Research in Chinese Societies, 2008, 30: $3-63$. 
[8] Cheng, B.S., Huang, M.P., \& Chou, L.F. Paternalistic leadership and its effectives: Evidence from Chinese organization teams[J]. Journal of Psychology in Chinese Societies, 2002, 3(1): 85-112.

[9] Wu, M., Huang, X., Li, C., \& Liu, W. Perceived interactional justice and trust-in-supervisor as mediators for paternalistic leadership[J]. Management and Organization Review, 2012, 8: 97-121.

[10] Chen, X. P., Eberly, M. B, Chiang, T.J., \& Cheng, B.P. Affective trust in Chinese leaders: Linking paternalistic leadership to employee performance[J]. Journal of Management, 2014, 40(3): 796-819.

[11] Zhang, X.A., He, H., \& Gu, F. The influence of paternalistic leadership on team performance: the mediating role of team conflict[J]. Management World, 2009, 3: 121-133.

[12] Tepper, B.J. Consequences of abusive supervision[J]. Academy of Management Journal, 2000, 43(2): 178-190.

[13] Farh J L, Cheng B S. A Cultural Analysis of Paternalistic Leadership in Chinese Organizations[M]. London: Macmillan, 2000.

[14] Cheng, B. S., Chou, L. F., Wu, T. Y., Huang, M. P., \& Farh, J. L. Paternalistic leadership and subordinate responses: Establishing a leadership model in Chinese organizations[J]. Asian Journal of Social Psychology, 2004, 7(1): 89-117.

[15] Mehrabian A, Russell J A. An approach to environmental psychology[M]. MIT, 1974.

[16] Liu, B., Qi, L., \& Xu, L. Spare the rod and spoil the child? A study on employee workplace deviant behavior[J]. Nankai Business Review, 2017, 20(3): 182-192.

[17] Bandura A. Social foundations of thought and action: A social cognitive theory[M]. Prentice Hall, 1986.

[18] Bandura, A. Moral disengagement in the perpetration of inhumanities[J]. Personality and Social Psychology Review, 1999, 3(3): 193-209.

[19] Fida, R., Paciellp, M., Tramontano, C., Fontaine, R.G., Barbaranelli, C., \& Farnese, C.B. An integrative approach to understanding counterproductive work behavior: The roles of stressors, negative emotions, and moral disengagement[J]. Journal of Business Ethics, 2015, 130(1): 131-144.

[20] Palmer N F. The effects of leader behavior on follower ethical behavior: Examining the mediating roles of ethical efficacy and moral disengagement[J]. Dissertations \& Theses-Gradworks, 2013.

[21] Brislin R W. Translation and Content Analysis of Oral and Written Material[J]. Handbook of Cross-cultural Psychology, 1980:389-444.

[22] Zhang, Y., LePine, J. A., Buckman, B. R., \& Wei, F. It's not fair or is it? The role of justice and leadership in explaining work stressor-job performance relationships[J]. Academy of Management Journal, 2014, 57(3): 675-697.

[23] Moore, C., Detert, J.R., Treviño, L.K., Baker, V.L., \& Mayer, D.M. Why employees do bad things: moral disengagement and unethical organizational behavior[J]. Personnel Psychology, 2012, 65(1): 1-48.

[24] Anderson, J. C., \& Gerbing, D. W. Structural equation modelling in practice: A review and recommended two-step approach[J]. Psychological bulletin, 1988, 103(3): 411-423.

[25] Hu, L. T., \& Bentler, P. M. Cutoff criteria for fit indexes in covariance structure analysis: Conventional criteria versus new alternatives[J]. Structural Equation Modelling: A Multidisciplinary Journal, 1999, 6(1): 1-55 
[26] Podsakoff, P. M., MacKenzie, S. B., Lee, J. Y., \& Podsakoff, N. P. Common method biases in behavioral research: a critical review of the literature and recommended remedies[J]. Journal of applied psychology, 2003, 88(5): 879-903.

[27] Hayes A F. Introduction to Mediation, Moderation, and Conditional Process Analysis: A Regression-Based Approach[M]. 2013.

[28] Otken, A.B., \& Cenkci, T. The impact of paternalistic leadership on ethical climate: the moderating role of trust in leader[J]. Journal of Business Ethics, 2007, 108(4): 525-536.

[49] Aycan, Z., Kanungo, R., Mendonca, M., Yu, K., Deller, J., Stahl, G., \& Kurshid, A. Impact of culture on human resource management practices: A 10-country comparison[J]. Journal of Applied Psychology, 2000, 49(1): 192-221. 